\title{
A Comparative Research on the Optimal Anchor Angle of Anchor Cable Frame Project
}

\author{
Xiao Tong ${ }^{1, a^{*}}$ \\ ${ }^{1}$ School of Geological Engineering and Geomatics, Chang'an University, Xi'an 710054, Shaanxi, \\ China \\ adexscience@163.com
}

Keywords: anchor cable frame; optimal anchorage angle; VB programming; calculation software Abstract. It often happens in anchor cable projects that the beams of anchor cable fail to exert the optimal effect or even the projects fail due to the irrational design of anchorage angle. In response to this, based on the principal theoretical formula, the expression of the optimal anchorage angle was deduced, taking the bending moment of beams of anchor cable. Relevant software was compiled. The validity of the results was verified. The calculation of the optimal anchorage angle under different theories was also researched to be compared with the results of this paper.

\section{Introduction}

The reinforcement technique for prestressed anchor cable frame refers to that the anchors of prestressed anchor cable is fastened to the frame structure, which frame, prestressed anchor cable and the foundation together take the load of the reinforcement structure ${ }^{[1]-[3]}$. In the design, except the designing parameters of the frame itself, the anchorage angle of the prestressed anchor cable is a very significant parameter ${ }^{[4]-[5]}$. Based on the Winkler foundation model, using backward beam method to calculate the internal force of anchor cable frame, the anchorage angle of the minimum bending moment is confirmed to be the optimal one.

\section{The deduction of the theoretical formula}

Let us suppose the anchor cable - frame-foundation system we are going to talk about is as shown in Fig.1.

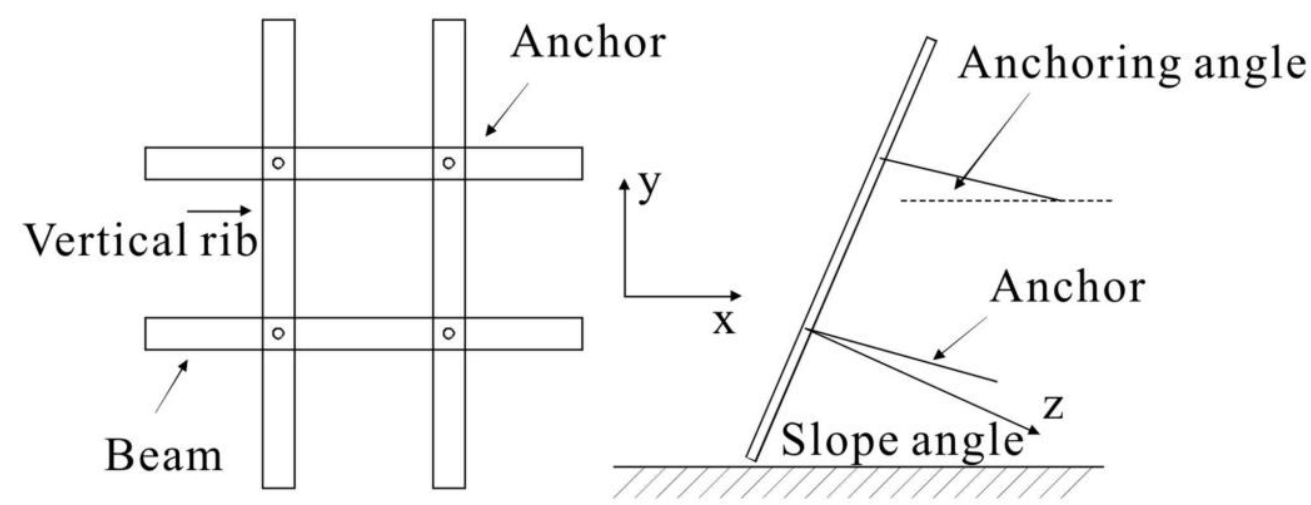

Fig. 1 Anchor cable frame diagram

For the distribution principle and calculation formula of forces on the beam and vertical rib, two important conditions are introduced in.

(1) Deformation compatibility condition: The beams are always in touch with the foundation soil. After deformation, the displacement generated by the intersections of the beams and vertical ribs must be equal. Namely,

$$
Z_{x}=Z_{y}=Z
$$

(2) Static equilibrium condition: The sum of forces distributed on the beam and the vertical rib should be equal to the component force in the direction vertical to the slope of the gross anchor cable force. Namely, 


$$
F \cos \left(90^{\circ}-\alpha-\beta\right)=F_{x}+F_{y}
$$

In this paper, we take the bending moment between beams and vertical ribs as the objective function. We have deduced that when the function gets the minimum value, the correspondent anchorage angle is the optimal. The expression for bending moment of beams is similar to that of vertical ribs, so we choose the beam as a research example. Here is its bending moment expression:

$$
M=\left(F_{x} / 4 \lambda\right) e^{-\lambda x}(\cos \lambda x-\sin \lambda x)
$$

In the expression: $M$ stands for bending moment; $F_{x}$ stands for the component force of anchor cable force on the beam.

$\lambda=\sqrt[4]{b k /(4 E I)}$ stands for flexibility Eigen value; $\mathrm{b}$ stands for the width of beam; $\mathrm{k}$ stands for the modulus of sub grade reaction; E stands for the elasticity modulus of the beam; I stands for the flexural rigidity.

In expression(3), it can be seen that bending moment $M$ changes according to the changes of $\mathrm{x} . \mathrm{M}$ derivation of $\mathrm{x}$, we get:

$$
d M / d x=-(F \cos \lambda x) /\left(2 e^{\lambda x}\right)
$$

When $d M / d x=0$ :

We get: $\cos \lambda \mathrm{x}=0$

Namely: $x=\pi /(2 \lambda)=1.57 / \lambda$ after sorting we can get:

$$
\lambda x=1.57
$$

Expression (5) illustrates that the maximum bending moment happens when $x=1.57 / \lambda$.

Substitute expression (5) into expression (3):

$$
M_{\max }=F_{x} /(4 \lambda) \times 0.2022176=F_{x} /(20 \lambda)
$$

In the expression: $F_{x}$ stand sor the component force of anchor cable force on the beam. Here is the expression.

$$
F_{x}=C_{a} F \cos (90-\alpha-\beta)
$$

In the expression: $C_{a}=\lambda_{y} b_{x} /\left(\lambda_{x} b_{y}+\lambda_{y} b_{x}\right)$, since the material parameter and sectional dimension of beams and vertical ribs in general projects are the same, so $b_{x}=b_{y} 、 \lambda_{x}=\lambda_{y}$

Expression (7) can be simplified into:

$$
F_{x}=0.5 \times F \cos (90-\alpha-\beta)
$$

Substitute expression (8) into expression (6), and we get:

$$
M_{\text {max }}=\frac{1}{40} \frac{F \cos (90-\alpha-\beta)}{\lambda}
$$

In expression(9), we can see that the soil parameters of sliding mass is constant and the design parameters of beams and vertical ribs are fixed value. The design tension of the prestressed anchor cable is fixed. Then the maximum bending moment is related with the slope angle $\alpha$ of the side slope and anchorage angle $\beta$. Namely, $f\left(M_{\max }\right)=f(\alpha, \beta)$. We suppose the slope angle $\alpha$ of the side slope is a constant, and anchorage angle $\beta$ is a variable. Derivation of $\beta$ :

$$
M_{\max } / d \beta=(1 / 40) \times(F \sin (90-\alpha-\beta) / \lambda)
$$

When, $d M_{\max } / d \beta=0, \sin (90-\alpha-\beta)=0$ then,$\alpha+\beta=90^{\circ}$ namely

$$
\beta_{\text {opt }}=90^{\circ}-\alpha
$$

According to the deduced formula(11), the included angle between the optimal anchorage angle $\beta_{\text {opt }}$ and the slope angle $\alpha$ of the side slope is $90^{\circ}$. 


\section{The compilation of calculation software for the internal force of anchor cable frame}

VB language is used for the software compilation in this paper. It offers a user-friendly interface and clear operation. The thinking of compiling this software is as shown in Fig. 2.Parameters input and results output are as shown in Table 1.

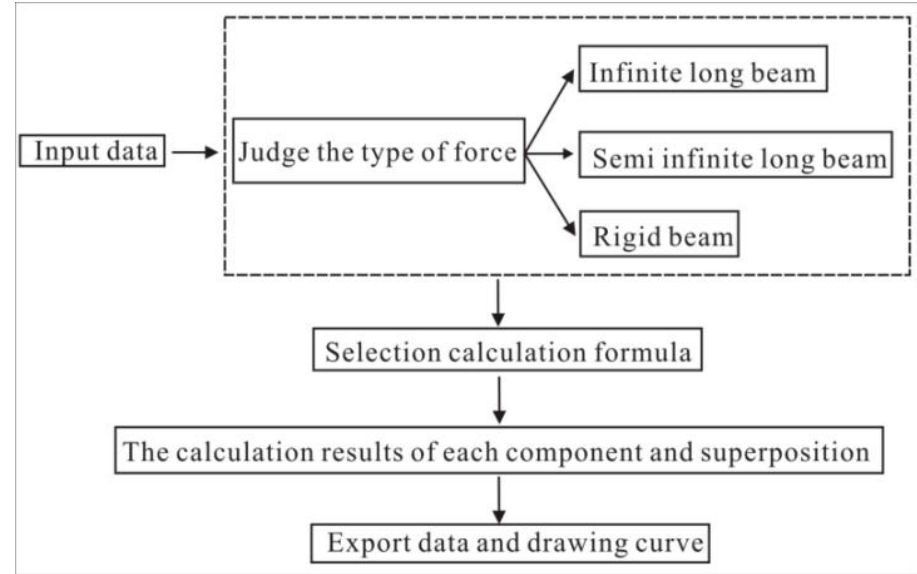

Fig.2 Software ideas flow chart

Table 1 The input and output table of the software

\begin{tabular}{|c|c|c|c|c|}
\hline \multirow{2}{*}{$\begin{array}{l}\text { Parameters } \\
\text { input }\end{array}$} & Design tension $\mathrm{F}$ & $\begin{array}{l}\text { Slope angle of side } \\
\text { slope }\end{array}$ & Anchorage angle & $\begin{array}{c}\text { Sectional dimension } \\
\mathrm{b}, \mathrm{h}\end{array}$ \\
\hline & $\begin{array}{l}\text { Frame geometric } \\
\text { dimension }\end{array}$ & $\begin{array}{l}\text { Sub grade reaction } \\
\text { modulus }\end{array}$ & $\begin{array}{l}\text { Material elasticity } \\
\text { modulus E }\end{array}$ & \\
\hline Result output & $\begin{array}{c}\text { Beam bending } \\
\text { moment }\end{array}$ & Beam shearing force & Beam deflection & \\
\hline
\end{tabular}

There is a project using prestressed anchor cable frame to do reinforcement. Every piece of the frame is composed of two beams and two vertical ribs, with 4 prestressed anchor cables. Every anchor cable is made of $4 \phi_{15}^{J}$ steel strand with design tension of $100 \mathrm{kN}$. The reinforced concrete frame adopts $\mathrm{C} 25$ concrete for spouting. The length of the vertical rib is $6 \mathrm{~m}$ while the length of the beam is $5 \mathrm{~m}$. The separation distance between vertical ribs is $2.5 \mathrm{~m}$ while that for beams is $2 \mathrm{~m}$. The slope angle of the side slope $=90^{\circ}$, and the anchorage angle $=30^{\circ}$. All frame dimensions are $\mathrm{b} \times \mathrm{h}=0.3 \times 0.4 \mathrm{~m}^{2}$

The reaction modulus of rock soil is $\mathrm{Kh}=2 \times 105 \mathrm{kN} / \mathrm{m}^{3}$. The flexibility modulus of $\mathrm{C} 25$ concrete is $2.85 \times 10^{7} \mathrm{kN} / \mathrm{m}^{2}$. Compute the shearing force, bending moment and deflection of the frame. Input all the parameters into the software and press the computing button. Check the graphs of shearing force, bending moment and deflection through their results sections. The calculation results will be stored in .txt form, which is convenient for later procession. The calculation results are as shown in Fig.3Fig.5. The calculation results can also be put into ORIGIN for plotting and analysis. As shown in Fig.6, it can be seen that the maximum bending moment, $-11.2 \mathrm{kN} \cdot \mathrm{m}$, appears at the site of $1.25 \mathrm{~m}$ and $3.75 \mathrm{~m}$.
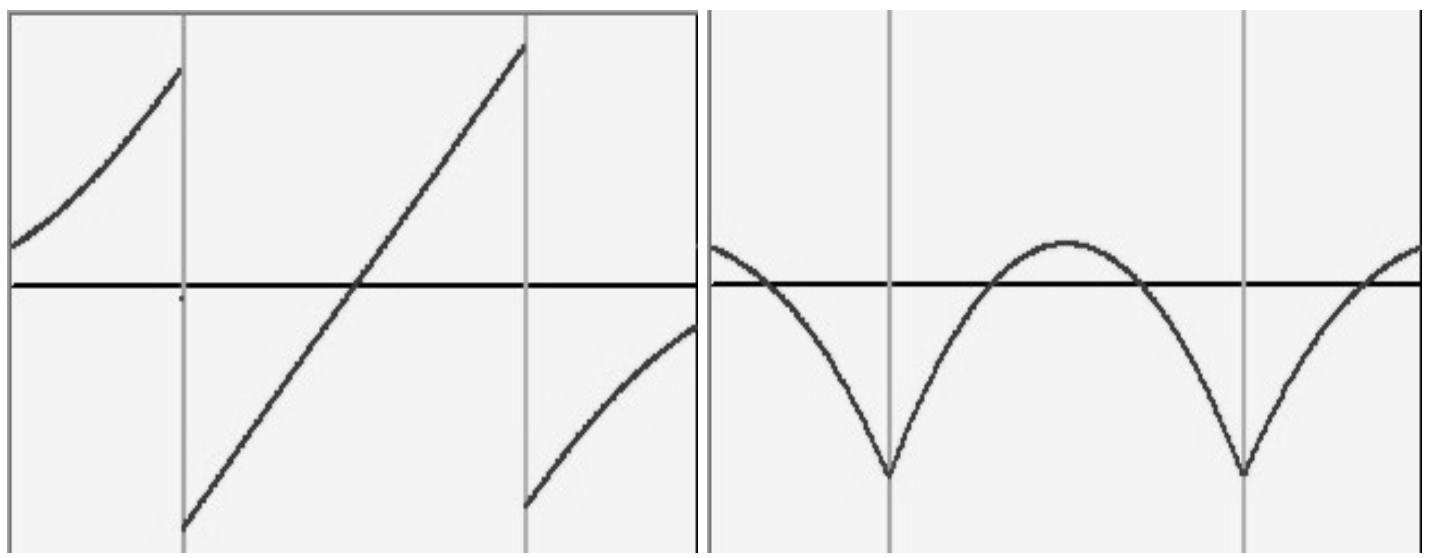

Fig.3 Beam shear force diagram ( unit: $\mathrm{kN}$ ) Fig.4 Beambending moment diagram ( unit: $\mathrm{kN} \cdot \mathrm{m}$ ) 

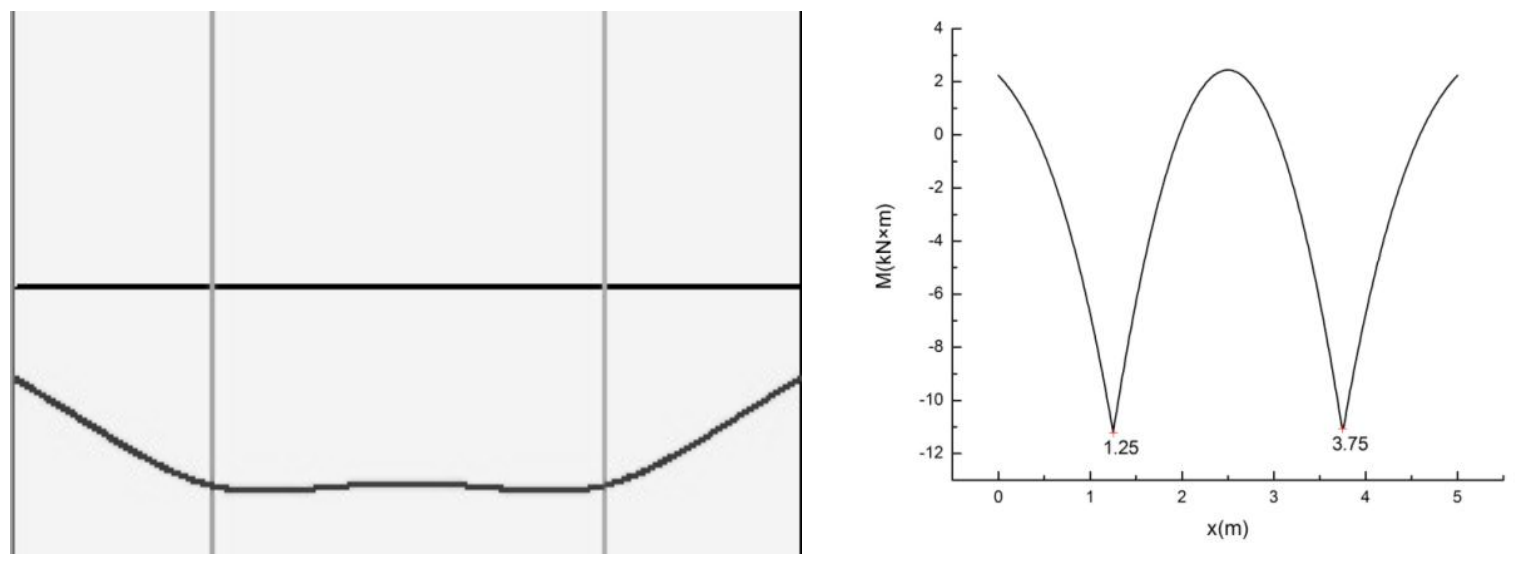

Fig.5 Beamdeflection diagram ( unit: $\mathrm{m}$ ) Fig.6 Beam bending moment diagram drawn in ORIGIN

\section{The verification of the calculation formula for the optimal anchorage angle}

In order to verify the design formula $\beta_{o p t}=90^{\circ}-\alpha$ deduced in this paper for the optimal anchorage angle, the calculation software for internal force of anchor cable frame is used. During the verification, the design tension $\mathrm{F}=100 \mathrm{kN}$. The frame constitutes 2 beams and 2 vertical ribs. The length of the vertical rib is $6 \mathrm{~m}$ while the length of the beam is $5 \mathrm{~m}$. The separation distance between vertical ribs is $2.5 \mathrm{~m}$ while that for beams is $2 \mathrm{~m}$. All the frame dimension is $\mathrm{b} \times \mathrm{h}=0.3 \times 0.4 \mathrm{~m}^{2}$. The reaction modulus of rock soil is $\mathrm{Kh}=2 \times 105 \mathrm{kN} / \mathrm{m}^{3}$. The flexibility modulus of $\mathrm{C} 25$ concrete is $2.85 \times 10^{7} \mathrm{kN} / \mathrm{m}^{2}$. Take bending moment as the objective function, we can get results shown in Table 2 and Fig. 7.

Table 2 The results of frame bending moment

\begin{tabular}{cccccc}
\hline $\begin{array}{l}\text { Anchorage } \\
\text { angle }\end{array}$ & $\alpha=10^{\circ}$ & $\alpha=20^{\circ}$ & $\alpha=30^{\circ}$ & $\alpha=40^{\circ}$ \\
\hline$\beta=0^{\circ}$ & 2.27 & 4.43 & 6.65 & 8.47 \\
\hline$\beta=10^{\circ}$ & 4.38 & 6.71 & 8.30 & 9.82 \\
\hline$\beta=20^{\circ}$ & 6.51 & 8.60 & 9.82 & 11.57 \\
\hline$\beta=30^{\circ}$ & 8.36 & 9.95 & 11.18 & 12.51 \\
\hline$\beta=40^{\circ}$ & 10.03 & 11.29 & 12.52 & 13.02 \\
\hline$\beta=50^{\circ}$ & 11.45 & 12.51 & 13.27 & 13.32 \\
\hline$\beta=60^{\circ}$ & 12.15 & 12.71 & 14.45 & 12.77 \\
\hline$\beta=70^{\circ}$ & 12.77 & 13.10 & 14.24 & 12.15 \\
\hline$\beta=80^{\circ}$ & 13.52 & 12.93 & 13.59 & 11.51 \\
\hline$\beta=90^{\circ}$ & 12.98 & 12.77 & 11.25 & 10.24 \\
& & & & & \\
\hline
\end{tabular}

Fig.7 Different anchoring angle beam bending moment diagram 
In the calculation chart, we can see when the slope angle of the side slope $\alpha=10^{\circ}$, the bending moment of the beams change according to the changes of the anchorage angle. When the anchorage angle $\beta=80^{\circ}$, the bending moment of the beams can reach the maximum. That is, under design tension $100 \mathrm{kN}$, the resistant fucntion of beam on side lsope reaches the maximum. Under this condition the effect of the achor cable reaches the best. The reasults meet the calculation formula of the optimal anchorage angle deduced in this paper, $\beta_{\text {opt }}=90^{\circ}-\alpha$, namely, $80^{\circ}=90^{\circ}-10^{\circ}$. From the verified results, we can see when the slope angle of side slope change into: $\alpha=20^{\circ}, \alpha=30^{\circ}, \alpha=40^{\circ}$, the copprespondant optimal anchorage angle are: $\beta=70^{\circ}, \beta=60^{\circ}, \beta=50^{\circ}$, which conform with the results of the theoretical formula.

\section{The comparison between methods for the optimal anchorage angle}

Through relevant Chinese and foreign documents, other methods for the optimal anchorage angle are found.

The first method: According to document, the result can be concluded as follows:

$\beta_{\text {opt }}=47.5^{\circ}-0.7 \alpha-9(1-\sin \phi)+8 F S R$ In the formula, $\alpha$ stands for slope angle of the

side slope $; \mathrm{K}=1-\sin \Phi, \quad F S R=F \frac{\tan \alpha}{\tan \phi}$, $\Phi$ stands for the internal friction angle of the soil; F stands for assurance factor ${ }^{[6]}$.

The 2nd method: in loess strata: $\beta_{o p t}=60^{\circ}-\phi$.In the formula, $\Phi$ stands for the internal friction angle of the soil ${ }^{[7]}$.

The 3rd method: $\beta_{o p t}=\frac{\pi}{4}+\frac{\phi}{2}-\alpha$.In the formula: $\Phi$ stands for the internal friction angle of the soil; $\alpha$ stands for slope angle of the side slope ${ }^{[8]}$.

The slope structure parameters and rock physical- mechanical indexes: sliding slope angle $\alpha=31^{\circ}$, the internal friction angle of the sliding slope, $\Phi=12^{\circ}$. The design tension of the anchor cable $\mathrm{T}=100$ $\mathrm{kN}$, and the cohesive force $\mathrm{c}=10 \mathrm{kPa}$. The design assurance factor $\mathrm{F}=1.12$. It needs to be indicated that slope shearing and sliding often occur during rainy season. Therefore, the shearing resistant strength indexes of the rock mass, c、 $\Phi$ are values in water-saturated state.

With different methods, the optimal anchorage angle can be acquired, as is shown in Chart 3.The calculation formula deduced in this paper, $\beta_{o p t}=90^{\circ}-31^{\circ}=59^{\circ}$ The first method:

$$
\begin{gathered}
\beta_{o p t}=47.5^{\circ}-0.7 \times 31^{\circ}-9\left(1-\sin 9^{\circ}\right)+8 \times 1.12 \frac{\tan 28^{\circ}}{\tan 20^{\circ}}=43.9^{\circ} \text { The second method: } \\
\beta_{o p t}=60^{\circ}-12^{\circ}=48^{\circ} \text { The third method: } \beta_{o p t}=\frac{\pi}{4}+\frac{31^{\circ}}{2}-12^{\circ}=41.5^{\circ} .
\end{gathered}
$$

Table 3 The calculation results of the optimal anchorage angle

\begin{tabular}{ccccc}
\hline The optimal anchorage angle & Formula of this paper & Method1 & Method2 & Method3 \\
\hline$\beta$ & $59^{\circ}$ & $43.9^{\circ}$ & $48^{\circ}$ & $41.5^{\circ}$
\end{tabular}

From the Table 3, we can see there are differences among the results of these four methods. The formula deduced in this paper is a basic one with the fewest factors to consider. It only needs the slope angle of the side slope and meets the elastic foundation beam theory. Thus, this method can be used for the design of the optimal anchorage angle at the initial design stage.

\section{Conclusions}

(1)The formula deduced in this paper for the optimal anchorage angle, $\beta_{o p t}=90^{\circ}-\alpha$, is applicable for practical projects, which can help design the optimal anchorage angle easily and fast. 
(2)The calculation software for the internal force of the anchor cable frame in this paper can help calculate the bending moment, shearing force and deflection under different conditions easily and fast. It also offers the function of curve plotting.

(3)In the comparison with other methods for the optimal anchorage angle, we can see there is no confirmed answer for designing the optimal anchorage angle, so general projects often adopt the experiential method.

\section{References}

[1] Nellen M. Optical Fiber Bragg Grating for Structural Monitoring in Civil Engineering J.16th Uongress of IABSE on Structural Engineering for Meeting Urban Transportation Challenges, 24(2003) 86-89.

[2] Sasiharan N, Muhunthan B, Badger TC, Shu S, Carradine DM Numerical analysis of the performance of wire mesh and cable net rockfall protection systems J. Eng Geol 88(2006) 121-132.

[3] Danziger FAB, Danziger BR, Pacheco MP The simultaneous use of piles and prestressed anchors in foundation design J . Eng Geol 87 (2006) 163-177.

[4] Sagaseta C, Sanchez JM, Canizal J ,A general analytical solution for the required anchor force in rock slopes with toppling failure J. Int J Rock Mech Min Sci 38(2001) 421-435.

[5] Dong, Wang, Application of full-length anchor support technology in a large-section roadway under complicated geological conditions J. J Coal Sci Eng .13(2012) 18:10. In Chinese.

[6] D. Hryciw, Anchor Design for Slope Stabilization by Surface Loading, J. Journal of Geotechnical Engineering. 117 (1991) 21-29.

[7] Wang, Xu, Liu, Landslide and landslide control technology, Bei Jing, 2004. Reference to a chapter in an edited book: In Chinese.

[8] Ren,Guo, Anchorage angle design of slope land beam anchor cable, J. Journal of water conservancy and Construction Engineering. 8 (2010) 310-314. In Chinese. 